\title{
Acute hyperammonemic encephalopathy secondary to ornithine transcarbamylase deficiency in a child:findings in diagnostic imaging
}

Encefalopatia hiperamonêmica aguda secundária à deficiência de ornitina transcarbamilase em uma criança: achados em exames de diagnóstico por imagem

Guilherme Marcelino de MIRANDA', Núria Avelar de Puertas MARCON, Caio Ferraz BASSO', Luiz Antônio JORGE JÚNIOR', Rodolfo Mendes QUEIROZ1.

A four-year-old girl presented with disorientation, drowsiness, anisocoria, tetraparesis and sialorrhea. She had shown significant behavioral changes over the previous six months. Computed tomography revealed bilateral involvement of the frontotemporoparietal and insular cortices, deep and subcortical white matter, confirmed by magnetic resonance imaging, which also showed signs of water diffusion restriction, hyposignal in T1-weighted sequence and no gadolinium enhancement (Figure). A prominent lactate peak was observed in spectroscopy. Urea cycle disorder was suspected after serum urea level was found to be 11 times higher than normal, which was confirmed after a genetic test was positive for heterozygous ornithine transcarbamylase deficiency ${ }^{1,2,3,4,5}$.
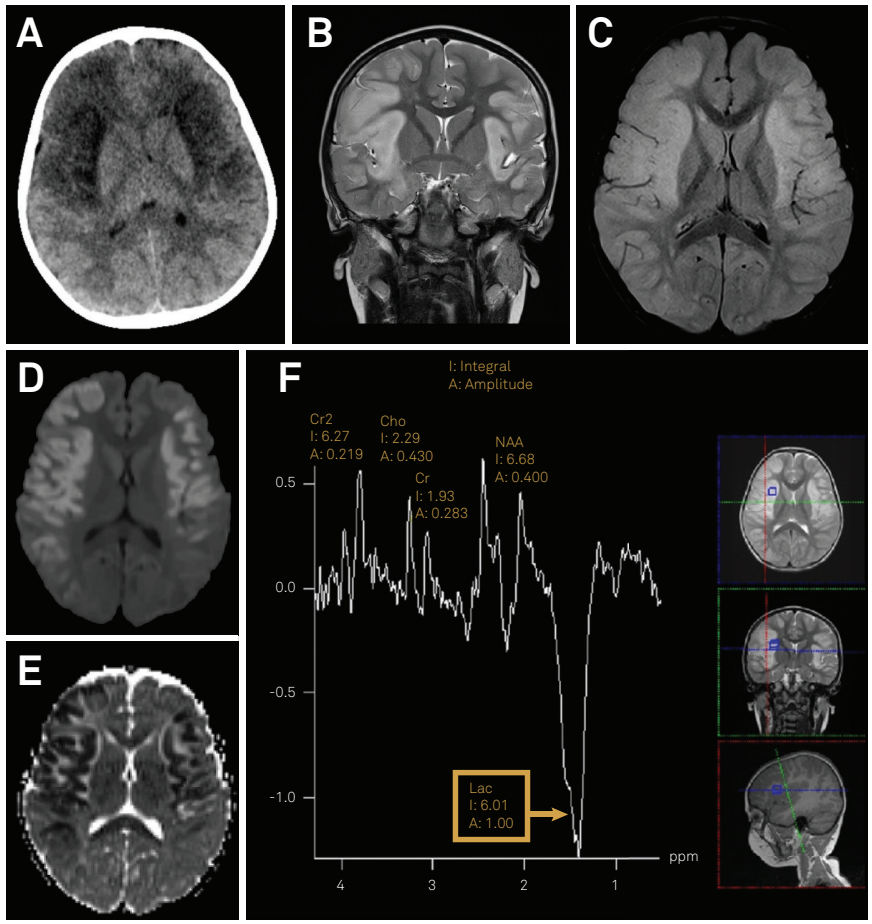

Figure. Computed tomography (A), showing extensive hypodensity affecting the deep and subcortical cerebral white matter mainly in areas of frontal, temporal, parietal and insular lobes bilaterally, predominantly symmetrical. Brain magnetic resonance imaging (B,C,D,E,F), showing in T2-weighted sequence (B) and FLAIR (C) a hyperintensity of the cortex, deep and subcortical white matter, notably in frontotemporoparietal and insular regions bilaterally. In the diffusion weighted imaging (D) and the apparent diffusion coefficient map (E), these areas showed marked hyperintensity and hypointensity respectively, characterizing a restriction of water diffusion. Spectroscopy (F) showed a prominent lactate peak (arrow). Since spectral data was obtained at an intermediate echo-time (135 ms), we could not assess glutamine/glutamate peaks, which, if present, would also point to hyperammonemia.

${ }^{1}$ Universidade do Estado de São Paulo, Faculdade de Medicina de Botucatu, Hospital das Clínicas, Radiologia e Diagnóstico por Imagem, Botucatu SP, Brasil; Rodolfo Mendes Queiroz (iD) https://orcid.org/0000-0002-4893-4422

Correspondence: Rodolfo Mendes Queiroz; Av. Professor Mário Rubens Guimarães Montenegro, s/n, Campus da UNESP; $18618-687$ Botucatu SP, Brasil;

E-mail: rod_queiroz@hotmail.com

Conflict of interest: There is no conflict of interest to declare.

Received 31 December 2018; Received in final form 27 March 2019; Accepted 21 April 2019. 


\section{References}

1. Häberle J, Boddaert N, Burlina A, Chakrapani A, Dixon M, Huemer M, et al. Suggested guidelines for the diagnosis and management of urea cycle disorders. Orphanet J Rare Dis. 2012 May;7:32. https://doi.org/10.1186/1750-1172-7-32

2. Posset R, Garbade SF, Boy N, Burlina AB, Dionisi-Vici C, Dobbelaere D, et al. Transatlantic combined and comparative data analysis of 1095 patients with urea cycle disorders-a successful strategy for clinical research of rare diseases. J Inherit Metab Dis. 2019 Jan;42(1):93-106. https://doi.org/10.1002/jimd.12031

3. Kurihara A, Takanashi J, Tomita M, Kobayashi K, Ogawa A, Kanazawa $M$, et al. Magnetic resonance imaging in late-onset ornithine transcarbamylase deficiency. Brain Dev. 2003 Jan;25(1):40-4 https://doi.org/10.1016/s0387-7604(02)00153-5

4. Takanashi J, Barkovich AJ, Cheng SF, Kostiner D, Baker JC, Packman S. Brain MR imaging in acute hyperammonemic encephalopathy arising from late-onset ornithine transcarbamylase deficiency. AJNR Am J Neuroradiol. 2003 Mar;24(3):390-3.

5. Merritt JL 2nd, Brody LL, Pino G, Rinaldo P. Newborn screening for proximal urea cycle disorders: current evidence supporting recommendations for newborn screening. Mol Genet Metab. 2018 Jun;124(2):109-13. https://doi.org/10.1016/j.ymgme.2018.04.006 